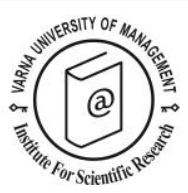

\title{
Koc, E. (2017). Service Failures and Recovery in Tourism and Hospitality: A Practical Manual, Oxfordshire: CABI Publishing. ISBN-13: 9781786390677
}

\author{
Reviewed by Ayhan Karakas ${ }^{1 *}$
}

Received: 22/11/2018

\begin{abstract}
1 Assistant Professor of Tourism Management, Faculty of Economic and Administration Sciences, Agdaci Campus, Bartin University, 00903782235354, E-mail: ayhankarakas74@gmail.com

* Corresponding author
\end{abstract}

(C) 2019 Varna University of Management. All rights reserved

Citation Koc, E. (2017). Service Failures and Recovery in Tourism and Hospitality: A Practical Manual, Oxfordshire: CABI Publishing. ISBN-13: 978178639067 7. Reviewed by Ayhan Karakas, European Journal of Tourism Research 21, pp. 158-160

This book consists of four parts and 14 chapters, with contributions from 26 authors. Considering the distribution of the authors' countries, the study is carried out through international participation.

The first chapter, authored by editor Erdogan Koc, is an introduction revealing the logical basis of the book, whereas Chapter 2, written by Christina K. Dimitriou, includes a literature review regarding the concepts of service failure and recovery via stating that any problem occurring in the service is defined as service failure and that service failures are caused by intangibility, heterogeneity/variability, inseparability, and perishability features of the services. The third chapter, authored by Melissa A. Baker, discusses theories and models on service failure and recovery such as expectancy disconfirmation paradigm, justice theory, etc. while stating that service failures not caused by the enterprise do not affect the perception of service failures and recovery.

The second part of the book examines the importance of emotions in service failure and recovery. Chapter 4, written by Erdogan Koc, Gulnil Aydin, Aybeniz Akdeniz Ar, and Hakan Boz, reviews the relationship between service failures and emotions. For measuring the emotions, using psychosocial tools is recommended rather than using conventional methods. This chapter suggests that the staff being able to detect, understand, control and manage customers' emotions as well as their own emotions is as important as measuring the customers' emotions (Koc, 2003).

In Chapter 5, Jong-Hyeong Kim defines the service failures to have a memorable nature and suggests the use of recovery strategies such as apology, correction, empathy, compensation, etc.

In Chapter 6, written by Beatrice P.T. Loo and Huey Chern Boo, the concept of attribution is addressed for explaining the reasons of service failures by exemplifying the aspects of attribution. The chapter also discusses the factors of customer attribution in reacting to service failures, and the topic is clarified by giving epitomes of those factors. 
Koc, E. (2017). Service Failures and Recovery in Tourism and Hospitality: A Practical Manual, Oxfordshire: CABI Publishing. ISBN-13: 978178639067 7. Reviewed by Ayhan Karakas, European Journal of Tourism Research 21, pp. 158-160

In Chapter 7, Minwoo Lee and Melissa A. Baker analyse the impacts of technology, systems, and people on service failures and recovery by stating that technology is now inevitable in providing services and ensuring satisfaction. This chapter compiles empirical evidence about the positive impacts of technology on customer satisfaction, behavioural intentions, and revisit intentions. The undeniable role of social media is examined within the scope of customer relations.

The eighth chapter, written by Petranka Kelly, Jennifer Lawlor, and Michael Mulvey, begins with the definition and classification of selfservice technologies in tourism establishments. Self-service technologies are said to ensure active customer participation in providing services such as online check-in, ticketing kiosks, and airport self-service bag-drop facilities, etc. While the benefits of self-service technologies are explained at great length through examples in this chapter, the influence of other customers in service failures and recoveries in terms of social facility theory, behaviour setting theory, and affective events theory is examined by Kawon Kim and Melissa A. Baker in Chapter 9. Here, environments affecting purchasing behaviour are regarded as the common feature of these theories. The service failure caused by another customer is defined as other customer service failure and classified according to the customer types. Because the context of service environments is the same for restaurants, hotels, and means of transportation, other customer service failures are said to be a lot higher in these services.

In Chapter 10, Celil Cakici and Ozan Guler cover the subjects of emotional contagion and group influence on service failure and recovery. Family, friends, and colleagues can be considered as examples of groups. Consumption is said to be increasing in the tourism sector when in groups and when complaints of those in a group are higher than individuals, as they affect each other. It is seen that emotional contagion is inevitable in the case of group services.
Part four addresses the topic of training in service failure and recovery. Chapter 11, written by Isil Arikan Saltik, Ugur Caliskan, and Umut Avci, emphasizes the importance of staff training in the context of service failure and recovery and lists staff training practices as orientation, job rotation, in-class training, coaching, group discussion, roleplaying, case study, and brainstorming.

In Chapter 12, Ali Dalgic, Derya Toksoz, and Kemal Birdir focus on the importance of employee empowerment, communication, and waiting time. Because service employees encounter service failures more than backstage employees, this issue can be dealt with by strengthened and autonomous employees. Another aspect is the establishment of organizational communication. The last part of this chapter focuses on the effort spent during service recovery.

Chapter 13, written by Erdogan Koc, examines the role of culture and the intercultural sensitivity. The fact that importance of positive social relations and the intercultural differences should be known is instantiated. The cultural dimensions theory of Hofstede (1984) is clearly reviewed from the perspective of service failure and recovery. To the question of whether service providers or managers should apologise to customers, it is stated that managers apologising rather than employees increases the customer satisfaction in highpower distance cultures. Service expectations are said to differ according to cultures, where individualism or collectivism, high risk-averse or low risk-averse, masculinity or femininity are dominant.

The last chapter, written by Anna Irimiás, Gábor Michalkó, Dallen J. Timothy, and Mariangela Franch, focuses on the disappointment in tourism and hospitality by explaining the concept of disappointment in the concept of movies. The effects of the movies on destination selection of tourists are explained through the examples of Balamory, Hobbiton, and Bollywood. It is possible to say that this chapter does not cohere with the content of the book. 
The fact that the book has online slides, provides learning outcomes, and includes assessment questions in each chapter makes it convenient for both students and educators. The book's chapters are supported by case studies and activities to ensure permanent learning. The students are encouraged to internalise and discuss subjects through these case studies. In addition, some tips are provided on how to use the information presented in the book in business life. The content of the book is logically organized. Its introduction and conclusion sections have the same format, and, while some chapters include case studies, others include discussion points and activity notes.

Not all sections are written in the same way because the authors are given the initiative for their paper by the editor. For instance, Chapter 10 provides brief information on the discussion points, but no additional information is given on the conclusion or recommendations. Providing tips or possible answers to the analysis of case studies at the end of the book would be useful for students. Because the concepts of service failures and service recovery are examined in various aspects such as theory, reasons, things to do for its training, how to behave according to individuals and groups, its relation with technology and intercultural differences, the book has the characteristics of a reference resource. To bring a small criticism, the aspect of service failures and recovery from the perspective of employees is examined only in Chapter 4 and 12, which could be further extended. The language of the book is fluent, and the terminology is presented in a way to be understood by the beneficiaries. This book can be used as a guidebook for students, educators, business executives, and researchers.

\section{References}

Hofstede, G. (1984). Cultural dimensions in management and planning. Asia Pacific Journal of Management, 1(2), 81-99.

Koc, E. (2003). The role and potential of travel agency staff as a marketing communications tool. Tourism Analysis, 8(1), 105-111. 